Laurent Papazian
Margaret Herridge

\section{Outcomes and risk stratification for severe ARDS treated with ECMO}

Received: 2 August 2013

Accepted: 6 August 2013

Published online: 17 August 2013

(C) Springer-Verlag Berlin Heidelberg and ESICM 2013

\section{Papazian}

Aix-Marseille University, URMITE CNRS-UMR 7278,

13005 Marseille, France

L. Papazian (

Réanimation des Détresses Respiratoires et Infections Sévères, APHM, Hôpital Nord, chemin des Bourrely, Réanimation, 13015 Marseille, France

e-mail: laurent.papazian@ap-hm.fr

Tel.: +33-491-965835

Fax: +33-491-965837

\section{Herridge}

Interdepartmental Division of Critical Care Medicine, University of Toronto, University Health Network,

11 Munk- 1180, 585 University Avenue,

Toronto, ON M5G 2N2, Canada

The acute respiratory distress syndrome (ARDS) is associated with a high mortality rate despite recent encouraging results from RCTs [1-3]. Initial profound hypoxemia is associated with the highest mortality rate [4]. In the subset of patients with the most severe hypoxemia $(\mathrm{PaO} 2 / \mathrm{FiO} 2$ ratio $<50-70)$ and/or when there is a high risk of severe ventilator-induced lung injury related to increased plateau pressure, some centers propose extracorporeal membrane oxygenation (ECMO) to minimize the trauma caused by mechanical ventilation and to promote lung rest and recovery. Biotechnological developments in the ECMO circuit, catheter and pump design have reinvigorated enthusiasm about using ECMO more than 20 years after initial disappointing results. In addition to enhanced technology, there is also a greater understanding of the nuances of patient management while on ECMO [5, 6]. The recent CESAR trial results [7] and the favourable outcomes of patients who received ECMO as rescue therapy during the recent H1N1 influenza pandemic support this [8-11]. However, many uncertainties remain about the use of ECMO in the most severe ARDS patients. We do not know at the present time if this intervention is able to decrease mortality compared to proning [1] or other ARDS-supportive treatments, nor do we understand specific morbidities related to catheter placement and prolonged circuit and anticoagulant exposure. Eligibility and selection criteria need to be informed by both mortality and morbidity outcome data, which are only just beginning to emerge $[12,13]$. The lung's ability to return to near-normal function after ARDS has been extensively reported [14]. We assume that pulmonary outcomes after ECMO will be similar, but what remains unclear are the other outcomes and in particular specific sequelae related to the application of this technology. As an example, placement of femoral cannulae may lead to ischemic nerve injury, and the resultant foot drop may have a profound impact on longer term function and mobility and other important patient and family-centered outcomes. These issues are of upmost importance because this intervention has very specific indications currently. First of all, ECMO is considered for the most hypoxemic patients. Although the relationship between hypoxemia and neurocognitive dysfunction was established by Hopkins and colleagues in 1999 [15], it remains unclear whether relatively brief hypoxemic exposures, for example, $\mathrm{a} \mathrm{PaO}_{2} / \mathrm{FiO}_{2}<50-70$ for several hours or days, would create substantial neuropsychological injury to justify early application of ECMO and the potential for other important long-term and potentially irreversible physical disabilities. We need detailed knowledge of how the components of ECMO therapy interact with the premorbid health status of our 
patients to understand the relative harm to different end organs, to determine individualized acquired risk and to establish a hierarchy of different risk exposures. In addition, neurological outcomes may also be altered by the risk of bleeding, which is increased by ECMO because of the use of anticoagulant therapy but also by the thrombocytopenia that is frequently associated with prolonged use of ECMO. Depressive symptoms and memory complaints are still persistent at least 5 years after ICU discharge post-ARDS [16], but we do not know if ARDS patients requiring ECMO present with similar, improved or even more compromised outcomes.

In the present issue, Schmidt et al. [6] report various long-term outcomes in 67 ARDS patients who were successfully treated by ECMO. Comparing these to previously published series of ARDS patients, they conclude that SF-36 scores compare favorably with prior cohorts treated with conventional mechanical ventilation strategies. They also do not report higher rates of anxiety and depressive symptoms than other series. This is a timely and interesting contribution to our knowledge about longterm outcomes after ECMO, but some limitations remain and warrant further evaluation. It would be useful to compare ARDS survivors who did and did not receive ECMO using the same methodology, respecting the same oxygenation goals and using an adequate case mix with comparable age, cause of ARDS and comorbidities. However, currently there are very few studies evaluating long-term outcomes in ECMO patients [7, 17], and this study is a notable contribution.

The most commonly used tool to assess health-related quality of life (HRQOL) is the Short Form-36 (SF-36) general health survey. It is a generic questionnaire that evaluates eight items from physical functioning to mental health. It was previously shown that surviving ARDS patients presented low SF-36 scores at 1 year [18-20]. Measuring only HRQOL does not give us the level of detail we need to understand morbidity or to help us construct rehabilitation programs to address specific limitations. HRQOL is too personal and subjective to give these detailed insights. Future work on ECMO outcomes would be strengthened by detailed physical, functional and neuropsychological outcome measures that help to inform the determinants of HRQOL in these patients.

One very important finding from the current study was the observation that low BMI was associated with poor outcome. We already understand that ICU-acquired weakness is an ubiquitous finding associated with severe critical illness and ARDS and that muscles undergo active proteolysis within hours of ICU admission. Premorbid muscle reserve is crucial to survival and restoring functional independence. One seminal contribution from this work may be the identification of low muscle mass as a key negative prognosticator that may be incorporated into more standardized ECMO eligibility criteria for future application and study.

Each of these discussion points needs to be answered prior to embracing ECMO as a standard treatment option and extending its indications to less hypoxemic patients. At the present time, it could be suggested to limit the ECMO indications to the most severely hypoxemic patients and/or when the criteria for protective mechanical ventilation are not fulfilled despite ventilator adjustments (Fig. 1). It is also important to evaluate the physical and neurocognitive impairments following ARDS treated by ECMO in order to understand whether
Fig. 1 Proposed algorithm for ECMO indications and areas of uncertainties

\section{Suggested ECMO indications}

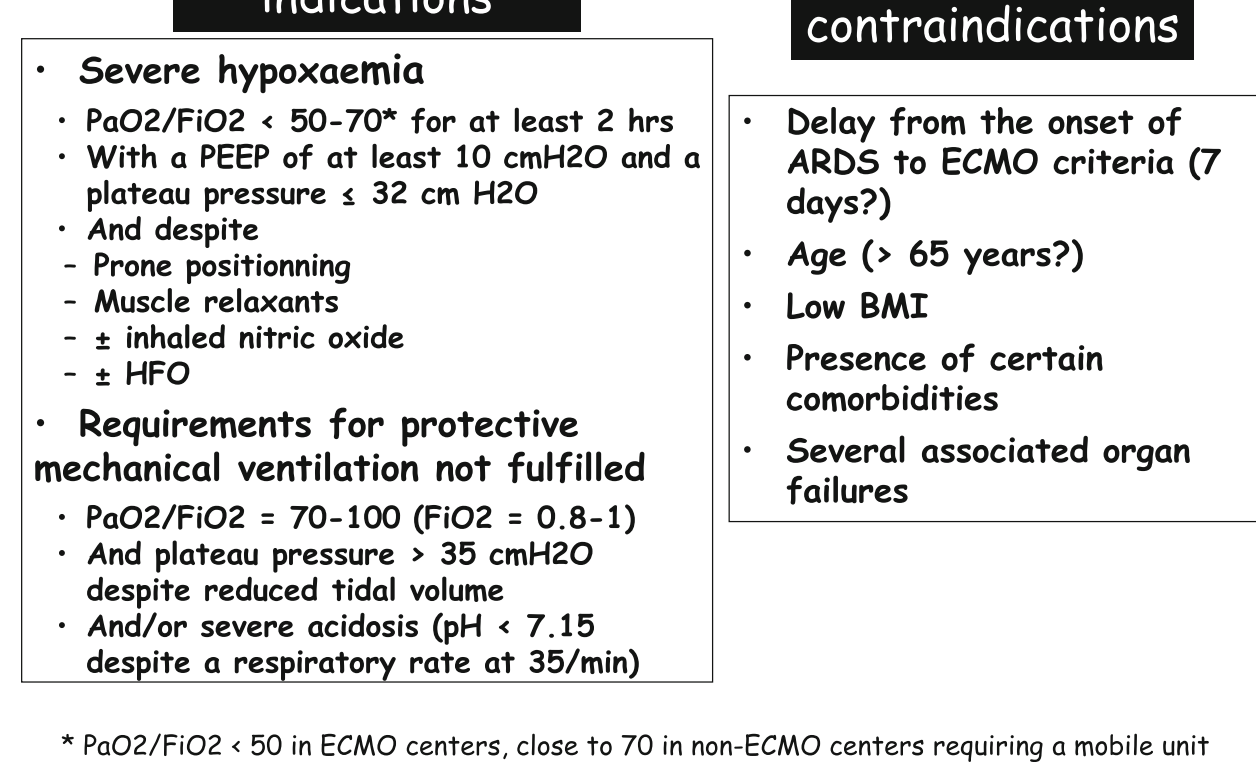

Emerging

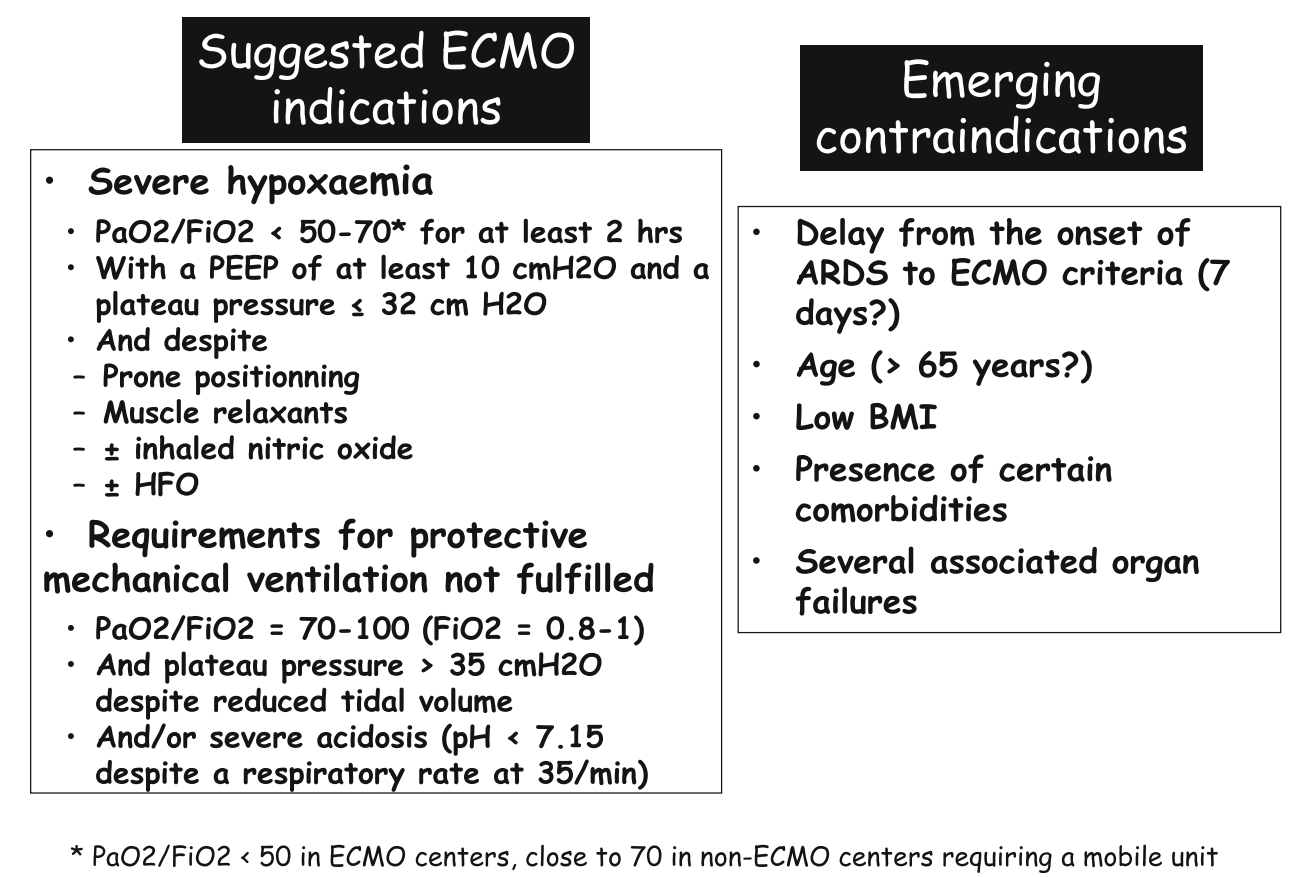


there are treatment-specific repercussions that require directed therapy or whether morbidity is comparable to what is already described in the ARDS outcome literature and being addressed through the design of multimodal rehabilitation programs. This should be the next step. Finally, we should not forget the burden on caregivers associated with the recovery of patients with lung injury
[14]. There are important and prolonged psychological impairments sustained by family members, which may also have an important negative effect on patients' recovery and rehabilitative potential.

Conflicts of interest On behalf of all authors, the corresponding author states that there is no conflict of interest.

\section{References}

1. Guerin C, Reignier J, Richard JC, Beuret P, Gacouin A, Boulain T, Mercier E, Badet M, Mercat A, Baudin O, Clavel M, Chatellier D, Jaber S, Rosselli S, Mancebo J, Sirodot M, Hilbert G, Bengler C, Richecoeur J, Gainnier M, Bayle F, Bourdin G, Leray V, Girard R, Baboi L, Ayzac L (2013) Prone positioning in severe acute respiratory distress syndrome. $\mathrm{N}$ Engl $\mathrm{J}$ Med 368:2159-2168

2. Papazian L, Forel JM, Gacouin A, Penot-Ragon C, Perrin G, Loundou A, Jaber S, Arnal JM, Perez D, Seghboyan JM, Constantin JM, Courant P, Lefrant JY, Guerin C, Prat G, Morange S, Roch A (2010) Neuromuscular blockers in early acute respiratory distress syndrome. N Engl J Med 363:1107-1116

3. Villar J, Blanco J, Anon JM, SantosBouza A, Blanch L, Ambros A, Gandia F, Carriedo D, Mosteiro F, Basaldua S, Fernandez RL, Kacmarek RM (2011) The ALIEN study: incidence and outcome of acute respiratory distress syndrome in the era of lung protective ventilation. Intensive Care Med 37:1932-1941

4. Ferguson ND, Fan E, Camporota L, Antonelli M, Anzueto A, Beale R, Brochard L, Brower R, Esteban A, Gattinoni L, Rhodes A, Slutsky AS, Vincent JL, Rubenfeld GD, Thompson BT, Ranieri VM (2012) The Berlin definition of ARDS: an expanded rationale, justification, and supplementary material. Intensive Care Med 38:1573-1582

5. Messai E, Bouguerra A, Harmelin G, Di Lascio G, Cianchi G, Bonacchi M (2013) A new formula for determining arterial oxygen saturation during venovenous extracorporeal oxygenation. Intensive Care Med 39:327-334
6. Schmidt M, Zogheib E, Rozé H, Repesse X, Lebreton G, Luyt CE, Trouillet JL, Bréchot N, Nieszkowska A, Dupont H, Ouattara A, Leprince P, Chastre J, Combes A (2013) The PRESERVE mortality risk score and analysis of long-term outcomes after extracorporeal membrane oxygenation for severe acute respiratory distress syndrome. Intensive Care Med. doi: 10.1007/s00134-013-3037-2

7. Peek GJ, Mugford M, Tiruvoipati R, Wilson A, Allen E, Thalanany MM, Hibbert CL, Truesdale A, Clemens F, Cooper N, Firmin RK, Elbourne D (2009) Efficacy and economic assessment of conventional ventilatory support versus extracorporeal membrane oxygenation for severe adult respiratory failure (CESAR): a multicentre randomised controlled trial. Lancet 374:1351-1363

8. Patroniti N, Zangrillo A, Pappalardo F, Peris A, Cianchi G, Braschi A, Iotti GA, Arcadipane A, Panarello G, Ranieri VM, Terragni P, Antonelli M, Gattinoni L, Oleari F, Pesenti A (2011) The Italian ECMO network experience during the 2009 influenza $\mathrm{A}(\mathrm{H} 1 \mathrm{~N} 1)$ pandemic: preparation for severe respiratory emergency outbreaks. Intensive Care Med 37:1447-1457

9. Pham T, Combes A, Roze H, Chevret S, Mercat A, Roch A, Mourvillier B, AraSomohano C, Bastien O, Zogheib E, Clavel M, Constan A, Marie Richard JC, Brun-Buisson C, Brochard L (2013) Extracorporeal membrane oxygenation for pandemic influenza $A(\mathrm{H} 1 \mathrm{~N} 1)$ induced acute respiratory distress syndrome: a cohort study and propensity-matched analysis. Am J Respir Crit Care Med 187:276-285

10. Roch A, Lepaul-Ercole R, Grisoli D, Bessereau J, Brissy O, Castanier M, Dizier S, Forel JM, Guervilly C, Gariboldi V, Collart F, Michelet P, Perrin G, Charrel R, Papazian L (2010) Extracorporeal membrane oxygenation for severe influenza A (H1N1) acute respiratory distress syndrome: a prospective observational comparative study. Intensive Care Med 36:1899-1905
11. Kumar A, Zarychanski R, Pinto R, Cook DJ, Marshall J, Lacroix J, Stelfox T, Bagshaw S, Choong K, Lamontagne F, Turgeon AF, Lapinsky S, Ahern SP, Smith O, Siddiqui F, Jouvet P, Khwaja K, McIntyre L, Menon K, Hutchison J, Hornstein D, Joffe A, Lauzier F, Singh J, Karachi T, Wiebe K, Olafson K, Ramsey C, Sharma S, Dodek P, Meade M, Hall R, Fowler RA (2009) Critically ill patients with 2009 influenza $\mathrm{A}(\mathrm{H} 1 \mathrm{~N} 1)$ infection in Canada. JAMA 302:1872-1879

12. Grasso S, Terragni P, Birocco A, Urbino R, Del Sorbo L, Filippini C, Mascia L, Pesenti A, Zangrillo A, Gattinoni L, Ranieri VM (2012) ECMO criteria for influenza A (H1N1)associated ARDS: role of transpulmonary pressure. Intensive Care Med 38:395-403

13. Pappalardo F, Pieri M, Greco T, Patroniti N, Pesenti A, Arcadipane A, Ranieri VM, Gattinoni L, Landoni G, Holzgraefe B, Beutel G, Zangrillo A (2012) Predicting mortality risk in patients undergoing venovenous ECMO for ARDS due to influenza A (H1N1) pneumonia: the ECMOnet score. Intensive Care Med 39:275-281

14. Herridge MS, Tansey CM, Matte A, Tomlinson G, Diaz-Granados N, Cooper A, Guest CB, Mazer CD, Mehta S, Stewart TE, Kudlow P, Cook D, Slutsky AS, Cheung AM (2011) Functional disability 5 years after acute respiratory distress syndrome. N Engl J Med 364:1293-1304

15. Hopkins RO, Weaver LK, Pope D, Orme JF, Bigler ED, Larson LV (1999) Neuropsychological sequelae and impaired health status in survivors of severe acute respiratory distress syndrome. Am J Respir Crit Care Med 160:50-56

16. Adhikari NK, Tansey CM, McAndrews MP, Matte A, Pinto R, Cheung AM, Diaz-Granados N, Herridge MS (2011) Self-reported depressive symptoms and memory complaints in survivors 5 years after ARDS. Chest 140:1484-1493 
17. Luyt CE, Combes A, Becquemin MH, Beigelman-Aubry C, Hatem S, Brun AL, Zraik N, Carrat F, Grenier PA, Richard JC, Mercat A, Brochard L, Brun-Buisson C, Chastre J (2012)

Long-term outcomes of pandemic 2009 influenza $\mathrm{A}(\mathrm{H} 1 \mathrm{~N} 1)$-associated severe ARDS. Chest 142:583-592

18. Angus DC, Musthafa AA, Clermont G, Griffin MF, Linde-Zwirble WT,

Dremsizov TT, Pinsky MR (2001)

Quality-adjusted survival in the first

year after the acute respiratory distress syndrome. Am J Respir Crit Care Med 163:1389-1394
19. Davidson TA, Caldwell ES, Curtis JR, 20. Herridge MS, Cheung AM, Tansey CM, Hudson LD, Steinberg KP (1999) Reduced quality of life in survivors of acute respiratory distress syndrome compared with critically ill control patients. JAMA 281:354-360 Saidi F, Cooper AB, Guest CB, Mazer
Matte-Martyn A, Diaz-Granados N, AlCD, Mehta S, Stewart TE, Barr A, Cook D, Slutsky AS (2003) One-year outcomes in survivors of the acute respiratory distress syndrome. N Engl J Med 348:683-693 